\title{
Availability and Quality of Family Planning Services in the City of Lubumbashi, Democratic Republic of Congo
}

\author{
Matungulu Matungulu Charles*, Ntambue Mukengeshayi Abel, Ilunga Kandolo Simon, \\ Mundongo Shamba Henry, Kakoma Sakatolo Zambeze Jean Baptiste, Malonga Kaj Françoise
}

Ecole de Santé Publique de l’Université de Lubumbashi, Lubmbashi, Democratic Republic of Congo

Email: *matungulu328@gmail.com

How to cite this paper: Charles, M.M., Abel, N.M., Simon, I.K., Henry, M.S., Baptiste, K.S.Z.J. and Françoise, M.K. (2019) Availability and Quality of Family Planning Services in the City of Lubumbashi, Democratic Republic of Congo. Open Access Library Journal, 6: e5208. https://doi.org/10.4236/oalib.1105208

Received: January 27, 2019

Accepted: February 25, 2019

Published: February 28, 2019

Copyright $\odot 2019$ by author(s) and Open Access Library Inc.

This work is licensed under the Creative Commons Attribution International License (CC BY 4.0).

http://creativecommons.org/licenses/by/4.0/

\begin{abstract}
Introduction: The long-term availability of contraceptive methods and the provision of quality planning services are bedrock for increasing contraceptive prevalence. The objectives of this study are to determine the coverage and availability of family planning (FP) services, as well as to evaluate the quality of these services in the city of Lubumbashi. Methods: From May to June 2017, we carried out a descriptive transversal study in several health facilities (HF) in the city of Lubumbashi. We have comprehensively included all the health facilities we have identified. The data were collected by interviews, documentary analyses and observation, guided by a questionnaire. We calculated the proportions for the different variables and the quality was evaluated using the score we built for this purpose. Results: Our study involved 570 health facilities. The coverage for family planning services was $0.7 / 10,000$ inhabitants. Their availability was $29.6 \%$ among the visited structures; $10.1 \%$ of HF had no contraceptives in stock, $10.1 \%$ had one to two contraceptives and $79.9 \%$ had three or more. The quality of FP services was good in the majority ( $82 \%$ ) of $\mathrm{HF}$, average in $12 \%$ and poor in $6 \%$ of the cases. Conclusion: The coverage of FP services and their availability in the city of Lubumbashi were low. The quality of family planning services was good in most health facilities offering FP services. Improving coverage and availability of family planning services in Lubumbashi, as well as the innovation of the most appropriate supply strategies, is essential to increase contraceptive prevalence.
\end{abstract}

\section{Subject Area}

Public Health 


\section{Keywords}

Family Planning, Contraceptive Methods, Contraception, Quality of Care

\section{Introduction}

Contraceptive methods could reduce maternal mortality by 29 percent and infant mortality by 10 percent each year if available to all who need it [1]. They improve the health of women and children and in the long run make women economically productive and active [2], family planning being a priority for all countries aspiring to development [3] [4]. However, contraceptive methods remain poorly used in Central Africa and DR Congo [2] [5]. Among 19\% of women who use any contraceptive method, $11 \%$ use a traditional method and only $8 \%$ use a modern method [6], and in the city of Lubumbashi, $23.5 \%$ of the $28.4 \%$ using any birth control use modern contraceptive methods compared to $4.9 \%$ using traditional methods [7]. On the other hand, unmet needs in FP are increasing in DR Congo (28\%) [2] [6]. In the DRC, women attend pre-natal consultations (PNC) (90\%), give birth in maternity wards $(80 \%)$, attend post-natal consultations (48\%) and have their newborns completely vaccinated (45\%) [6]. All of these mothers could proportionally benefit from all these family planning services. For the city of Lubumbashi, $92.6 \%$ of women who have given birth follow pre-natal consultation, $93.8 \%$ give birth in a health facility, $97.2 \%$ give birth in the presence of a qualified health staff and $36.4 \%$ attend post-natal consultation [8]; however, FP services remain the most important part of the maternal health package. In addition, family planning is an integral part of primary health care (PHC), which constitutes the health policy of the DRC [9]. As such, FP is part of the minimum package of activities of the health center and the complementary package of activities of the general referral hospital [10]. Making contraceptive methods available and providing quality care to clients is a major pedestal for the provision of family planning services [11].

According to Shireen et al., improving health services in general and FP in particular can have a direct influence on increasing contraceptive prevalence [12]. In 2009, a conference was held in Kinshasa to promote the repositioning of family planning in health interventions to improve the health of mothers, newborns and children [13]. By 2020, the DRC wants to offer FP services to 2.1 million new accepting in order to achieve a modern contraceptive prevalence of $19 \%$ across the country [14]. Making FP services accessible and usable is one of the levers for achieving this goal.

This study aimed to determine the coverage of the city of Lubumbashi in family planning services, to identify the methods of contraception available in health facilities (HF) and to assess the quality of FP services provided to clients in the health facilities concerned. 


\section{Methods}

To achieve these objectives, we carried out a cross-sectional descriptive study in the health facilities of the city of Lubumbashi, from May to July 2017. We comprehensively included all the health structures identified during the survey, in 10 Health Zones (health districts) of the city of Lubumbashi (Kamalondo, Kampemba, Katuba, Kenya, Kowe, Lubumbashi, Mumbunda, Rwashi, Tshamilemba and Vangu); all functional Health Areas have been included. For the two Special Health Zones (Kowe and Vangu), only structures present in the city of Lubumbashi were visited. The Kisanga Health Zone was excluded due to the inciden that led to the looting and burning of the Central Office and the Reference General Hospital on December 19, 2017. These 10 Health Zones cover a population estimated at 2,405,301 inhabitants in 2017, or 505,113 women of childbearing age $(21 \%)$. We recruited, selected and trained the interviewers who collected the data. The sketches and lists of the Central Offices of Health Zones allowed us to identify the recognized structures. For non-integrated health facilities, the snowball technique helped us to identify them. In practice, in each structure, a question was asked to the respondent to verify the existence of another structure in the Health Area, and the structure was automatically visited. The interview technique guided by a questionnaire enabled us to collect the data; the information collected was validated after the documentary analysis (PF register) and the direct observation which focused on the verification of FP inputs in stock, furniture and other necessary materials. The quality of FP services, although complex [15], was evaluated according to the following criteria: presence of a document containing guidelines on the use of contraceptive methods (score: 3), presence of at least one member of the staff trained in family planning (score: 5), the offer of at least three contraceptive methods [16] including at least two modern (score: 7), presence of a local for counseling guaranteeing confidentiality (score: 3), existence of at least one fixed day per week spent on FP (score: 1) and possession of a FP data collection document including the FP register and PF cards (score: 2). Thus, the total score was 21 . The interpretation was as follows: $1-10=$ poor quality of services; $11-15=$ average quality of services; 16 21 = good quality of services.

The collected data were encoded in Excel and analyzed with the Epi Info version 7 software. The proportions of the different variables were calculated.

\section{Results}

In this study we included 570 health facilities (HF) identified in the ten Health Zones visited. The health coverage was 2.4 health facilities/10,000 inhabitants and the family planning services coverage in the city of Lubumbashi was $0.7 / 10,000$ inhabitants.

On the other hand, the availability of family planning services in the health facilities was 29.6\% (169/570). Of those who organized FP services, $74.6 \%$ were private facilities, $14.2 \%$ were state-owned and $11.2 \%$ were faith-based. Those 
who did not organize FP services were all private ( 89 Health facilities). The reasons given were the lack of partners, material/resources and training in FP. The majority of the visited facilities which were offering FP services (95.3\%) had at least one staff trained in Family Planning, compared to $4.7 \%$ who did not. The oldest training was in 2013, for the health facilities who cited the date of the last training. However, 61 health facilities (37.9\%) out of 161 with trained staff did not mention the date, or the year and even less the month of the last FP training. The most cited occupational category in charge of family planning in health facilities was the A1 (graduate) nurses, who were present in 100 structures (59.2\%), followed by general practitioners $(38,5 \%)$ and A2 nurses (36.1\%); A3 nurses were less present in FP services (13.6\%). The proportion of facilities with FP-trained physicians providing FP services was relatively low $(69.2 \%$ and $62.5 \%$, respectively, of the facilities with trained generalist physician and gynecologists and obstetricians trained in FP). On the other hand, Table 1 shows that the health facilities who had at least one graduate nurse in charge of FP, were more likely to have trained in FP in $81 \%$ of cases. We observed that three out of four (75.1\%) structures did not have a document containing guidelines on the use of contraceptive methods against $24.9 \%$ who had a module or training support in FP: a syllabus, a book, the technical sheet of PF or the disc for the choice of methods and leaflets; PF data collection tools (registers or PF card) were present in 145 structures (85.8\%) and absent in 24 (14.2\%). Possession of a FP counseling room guaranteeing confidentiality was recorded in $87.6 \%$ of the HF and not found in $12.42 \%$ of these. Table 2 shows that an appropriate space for educational talks and customer awareness was present in 144 health facilities (85.2\%) and absent in 25 (14.8\%) of them. FP educational materials were present in $76.9 \%$ of the visited structures (Table 2). We observed that 114 structures (67.5\%) had at least one fixed day of FP during the week compared to 55 (32.5\%) who did not have one. The effectiveness of FP activities seemed to be weak. Table 3 indicates that during the past six months prior to the survey, more than one-third of the facilities did not carry out the planned FP sessions; those who organized at least one session per week accounted for $23.1 \%$ of the total. More than half did not organize any sessions in the community and $7.1 \%$ organized at least one session per week. Similarly, the total number of new acceptors in the first quarter of 2017 was 1738 customers and the number of former acceptors was 1103 customers. Table 4 indicates that the vast majority $(98.8 \%)$ of the health facilities received less than 50 clients during this period, reflecting the low FP activity in the majority of the health facilities and the low use of contraceptive methods by the population of Lubumbashi.

Table 5 shows that the contraceptive methods offered in the health facilities were the male condom (90.5\%), the pill (82.2), the female condom $(81.7 \%)$, the implants (72.8\%), the injectable (68,6\%), IUD (49.7\%), an emergency pill (48.5\%), the tubal ligation $(18.9 \%)$, the vasectomy (17.2\%), the cycle collar (62\%), periodic abstinence according to schedule (74.0\%) and LAM (68.6\%) (Table 5). We 
found that ten health facilities (5.9\%) offered fewer than three methods to clients compared to 159 (94.1\%) who offered three or more.

Table 1. Qualification of providers of family planning services in health facilities.

\begin{tabular}{ccc}
\hline Professional category & $\begin{array}{c}\text { Effective } \\
\mathbf{n}=169(\%)\end{array}$ & $\begin{array}{c}\text { Trained } \\
\mathbf{n}(\%)\end{array}$ \\
\hline Gynecologist/obstetrician & $32(18.9)$ & $20(62.5)$ \\
Generalist physician & $65(38.5)$ & $45(69.2)$ \\
Registered nurse (A0) & $56(33.1)$ & $43(76.8)$ \\
Nurse graduate (A1) & $100(59.2)$ & $81(81.0)$ \\
Nurse A2 & $61(36.1)$ & $50(82.0)$ \\
Nurse A3 & $23(13.6)$ & $14(60.9)$ \\
\hline
\end{tabular}

Table 2. Possession of materials and equipment needed for family planning services.

\begin{tabular}{ccc}
\hline Material/equipment & Effective $(\mathbf{n}=\mathbf{1 6 9})$ & Percent \\
\hline FP guideline document & 42 & 24.9 \\
Room for educational & 144 & 85.2 \\
Counseling room & 153 & 90.5 \\
Real estate in the counseling room & 140 & 82.8 \\
Calendar & 144 & 85.2 \\
Gynecological table & 131 & 77.5 \\
FP sheet & 137 & 81.1 \\
FP Appointment card & 120 & 71.0 \\
Register & 145 & 85.8 \\
FP support for educational & 130 & 76.9 \\
\hline
\end{tabular}

Table 3. Number of family planning sessions held in the 6 months prior to the survey, in the health facilities and in the community.

\begin{tabular}{ccc}
\hline Activities & Effective & Percent \\
\hline Number of sessions in last 6 months in the health facilities & \\
\hline None & 51 & 30.2 \\
$1-5$ & 51 & 30.2 \\
$6-11$ & 17 & 10.1 \\
$12-23$ & 11 & 6.5 \\
24 and over & 39 & 23.1 \\
Total & 169 & 100.0 \\
\hline Number of sessions in last 6 months in the community/home visit & \\
None & 86 & 50.9 \\
$1-5$ & 42 & 24.9 \\
6 - 11 & 18 & 10.7 \\
$12-23$ & 11 & 6.5 \\
24 and over & 12 & 7.1 \\
Total & 169 & 100.0 \\
\hline
\end{tabular}


Table 4. Old and news accepting to contraceptive methods in 2016 and the first quarter of 2017.

\begin{tabular}{|c|c|c|}
\hline User's number & Effective & Percent \\
\hline \multicolumn{3}{|l|}{ News accepting } \\
\hline 0 & 11 & 6.5 \\
\hline $1-10$ & 43 & 25.4 \\
\hline $11-20$ & 18 & 10.7 \\
\hline $21-30$ & 15 & 8.9 \\
\hline $31-40$ & 5 & 3.0 \\
\hline $41-50$ & 6 & 3.6 \\
\hline 51 and over & 4 & 2.4 \\
\hline No-existents data & 67 & 39.6 \\
\hline Total & 169 & 100 \\
\hline Total new accepting & 1738 & \\
\hline Total new accepting in 2016 & 3330 & \\
\hline \multicolumn{3}{|l|}{ Old accepting } \\
\hline 0 & 96 & 56.8 \\
\hline $1-10$ & 41 & 24.3 \\
\hline $11-20$ & 12 & 7.1 \\
\hline $21-30$ & 8 & 4.7 \\
\hline $31-40$ & 6 & 3.6 \\
\hline $41-50$ & 3 & 1.8 \\
\hline 51 and over & 3 & 1.8 \\
\hline Total & 169 & 100 \\
\hline Total of old accepting & 1103 & \\
\hline Old accepting in 2016 & 1897 & \\
\hline Administrative contraceptive prevalence 1st trimester in 2017 & 2841 & 0.6 \\
\hline Administrative contraceptive prevalence in 2016 & 5227 & 1.0 \\
\hline
\end{tabular}

Table 5. Contraceptive methods offered and in stock in health facilities and health coverage by contraceptive method.

\begin{tabular}{cccc}
\hline \multirow{2}{*}{ Methods } & Offer & In stock & Coverage by method \\
\cline { 2 - 4 } & $\mathrm{n}=169(\%)$ & $\mathrm{n}=169(\%)$ & (Health facility/inhabitants) \\
\hline Male condom & $153(90.5)$ & $127(75.1)$ & $1 / 15,721$ \\
Female condom & $138(81.7)$ & $119(70.4)$ & $1 / 17,430$ \\
Pill & $139(82.2)$ & $118(69.8)$ & $1 / 17,304$ \\
Emergency pill & $82(48.5)$ & $65(38.5)$ & $1 / 29,333$ \\
Injectable & $116(68.6)$ & $89(52.7)$ & $1 / 20,735$ \\
IUD & $84(49.7)$ & $60(35.5)$ & $1 / 28,635$
\end{tabular}




\section{Continued}

\begin{tabular}{cccc}
\hline Implants & $123(72.8)$ & $101(59.8)$ & $1 / 19,555$ \\
Spermicide & $41(24.3)$ & $22(13.0)$ & $1 / 58,666$ \\
Patch & $17(10.1)$ & $9(5.3)$ & $1 / 141,488$ \\
Diaphragm & $13(7.7)$ & $15(8.9)$ & $1 / 185,023$ \\
Tubal ligation & $32(18.9)$ & & $1 / 75,166$ \\
Vasectomy & $29(17.2)$ & & $1 / 82,941$ \\
Necklace of the cycle & $106(62.7)$ & $88(52.1)$ & $1 / 22,692$ \\
Calendar & $125(74.0)$ & & $1 / 19,242$ \\
LAM & $116(68.6)$ & & $1 / 20,735$ \\
FP sheet & & $99(58.6)$ & \\
Appointment Card & & $0(0)$ & \\
\hline
\end{tabular}

We found that the contraceptive methods and the materials that were in the stock the day of the visit were the male condom (75.1\%), the female condom (70.4\%), the pill (69.8\%), the implants (59.8\%), an injectables (52.7\%), an emergency pills (38.5\%), IUDs (35.5\%), spermicides (13.0\%), cycle collar $(52.2 \%)$, the PF card (58.6\%) and the appointment card (0\%); that same day, $10.1 \%$ of facilities had no contraceptives in stock, $10.1 \%$ had one to two and $79.9 \%$ had three or more.

We found that contraceptive health coverage was less than one structure per 10,000 population. In the last six months prior to the survey, only $61.5 \%$ of health facilities were supervised in family planning compared to $39.5 \%$ who had received no supervision. The supervisors were the Ministry of Health's peripheral (health district) or intermediary health officers as well as the Family Planning partners of the Ministry of Health (USAID, PROVIC, ASF, ABF, ICAP, DKT, UNFPA, and UNICEF). We noted the presence of family planning partners in $47.9 \%$ of the structures visited; $71 \%$ of the facilities benefited from the partnership of the Ministry of Health and partners compared to 30\% who did not benefit from this support. Figure 1 demonstrated that the quality of FP services was good in majority (82\%), average in $12 \%$ of the structures and poor in $6 \%$ of these. We observed that $91.7 \%$ of the state structures offered good quality services against respectively $89.4 \%$ and $78.6 \%$ of the confessional and private structures.

\section{Discussion}

Coverage for family planning services was low and lower than total health coverage. The total health coverage is growing in Lubumbashi; it was 1.5/10,000 inhabitants in 2006 [17]. This low coverage of family planning services may reflect the lack of prioritization of these services by health care providers and as a result explain low contraceptive prevalence. 


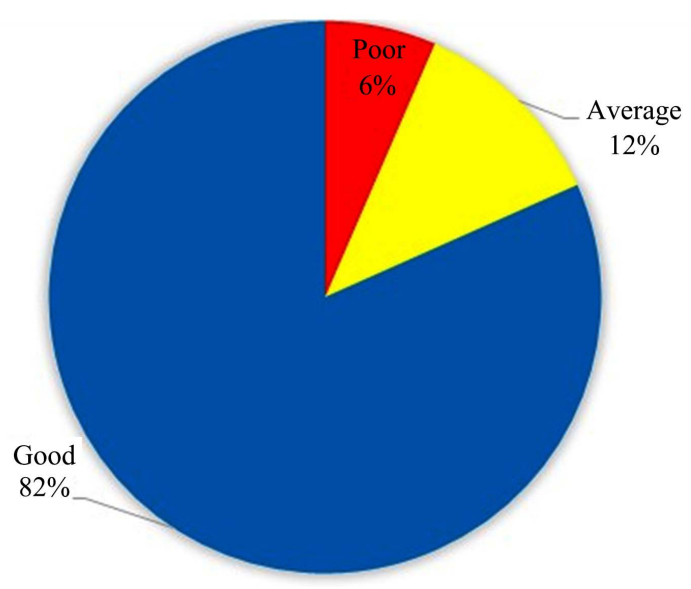

Figure 1. Quality of family planning services in health facilities in Lubumbashi.

Availability of family planning services was low. In Kinshasa, it was $78 \%$ in the public sector and $30 \%$ in the private sector; overall, availability was low [18]. This low availability may partly explain the low use of contraceptive methods in Lubumbashi. This low availability has also been reported by Mpunga et al. in DR Congo (33\% in general and $38.1 \%$ in urban areas) [19]; however, these authors have used the Ministry of Health's administrative database, which is derived from the commonly unreliable national health information system. In Kinshasa, the availability of FP in health facilities was $84 \%$ [20]; however the sample size of 184 health facilities used by the authors in Kinshasa seem to be an insufficient number for a statistically significant and representative sample. On the other hand, in Malawi, Kenya and Haiti, the availability of family planning services was higher than the one observed in Lubumbashi, with $83 \%, 88 \%$ and $84 \%$ respectively of health facilities surveyed [21]. Such low availability represents a real bottleneck for the increase in contraceptive prevalence in DR Congo and particularly in Lubumbashi: this seems unfortunately logical given the low prevalence of contraception.

We noted that almost $3 / 4$ of the health facilities that offered FP services were private facilities. This demonstrates the outstanding prevalence of private health facilities in the provision of health services generally in urban areas, exacerbated by the over-production of health personnel seeking employment, striving to provide health care of doubtful and even dehumanizing quality [22]. The private structures are usually lucrative. The predominance of the private sector has also been reported in Kenya [23], as well as in Ghana and Tanzania [24]. Its regulation and supervision are imperative.

Only $79.9 \%$ of the structures had three or more contraceptives in stock. These results are higher than those obtained in 2013 in DR Congo, which was $48.5 \%$ for the whole country [18]. Time could explain this difference, as well as the national coverage of this latest study, which also covered the often underprivileged rural environment. 
In our study, here family planning services were offered; they were mostly of good quality (82\%), despite their low utilization. Mpunga et al. concluded that $20 \%$ of family planning services in RD Congo were generally of high quality and $35.1 \%$ were in urban areas [19]. The different methods used to measure quality in the two cases could explain this difference. Bertrand et al. found that in Kinshasa only $44 \%$ of facilities offered good quality family planning services [20]; the uneven support of the Ministry of Health's partners in the country could explain the differences in our results.

The consideration of client satisfaction and the observation of the counseling process may complement the analysis of the quality of services. Therefore, the standardization of the measure for the quality of family planning services is a necessity. Similarly, a qualitative study on the underlying reasons for non-use of contraceptive methods, despite the good organizational quality of services, is imperative.

\section{Conclusion}

We have shown in this study that family planning coverage and availability are low in the city of Lubumbashi. Contraceptives were in stock in most health facilities that organized family planning services. However, methods were poorly used where available. Family planning services were of good quality in most of the health facilities. Improving coverage and availability of family planning services in Lubumbashi, as well as innovative best-fit delivery strategies and incentives, is key to increasing contraceptive prevalence.

\section{Acknowledgements}

We express our gratitude to the "Renforcement Inconstitutionnel pour les Politiques de Santé basées sur l'Evidence au Congo" (RIPSEC) program, which has well-funded this study.

\section{Conflicts of Interest}

The authors declare no conflicts of interest regarding the publication of this paper.

\section{References}

[1] Ahmed, S., Li, Q., Liu, L., Tsui, A.O., Bill, F. and Foundation, M.G. (2012) Maternal Deaths Averted by Contraceptive Use: An Analysis of 172 Countries. The Lancet, 380, 111-125. https://doi.org/10.1016/S0140-6736(12)60478-4

[2] Alkema, L., Kantorova, V., Menozzi, C. and Biddlecom, A. (2013) National, Regional, and Global Rates and Trends in Contraceptive Prevalence and Unmet Need for Family Planning between 1990 and 2015: A Systematic and comprehensive analysis. The Lancet, 381, 1642-1652. https://doi.org/10.1016/S0140-6736(12)62204-1

[3] Kuang, B. (2016) Global Trends in Family Planning Programs, 1999-2014. International Perspectives on Sexual and Reproductive Health, 42, 33. 
https://doi.org/10.1363/42e0316

http://www.jstor.org/stable/10.1363/42e0316

[4] Habumuremyi, P.D. and Zenawi, M. (2012) Making Family Planning a National Development Priority. The Lancet, 380, 78-80.

https://doi.org/10.1016/S0140-6736(12)60904-0

[5] Darroch, J.E. and Singh, S. (2013) Trends in Contraceptive Need and Use in Developing Countries in 2003, 2008, and 2012: An Analysis of National Surveys. The Lancet, 381, 1756-1762. https://doi.org/10.1016/S0140-6736(13)60597-8

[6] Ministère de la santé et suivi de la mise en oeuvre de la modernité (2014) Deuxième enquête démographique et de santé (EDS-RDC II 2013-2014). Ministère de la santé et suivi de la mise en oeuvre de la modernité, Kinshasa.

[7] Matungulu, C.M., Ntambwe, M.A., Ilunga, K.S., Musau, N.A., Ilunga, M.T. and Malonga, K.F. (2017) Factors Associated with the Use of Modern Contraceptive Methods by Women in Marital Union in the City of Lubumbashi, Democratic. Austin Journal of Women's Health, 4, 1022-1021.

[8] Ntambue, M.A., Malonga, K.F., Dramaix-Wilmet, M. and Donnel, M.P. (2012) Determinants of Maternal Health Services Utilization in Urban Settings of the Democratic Republic of Congo-A Case Study of Lubumbashi City. BMC Pregnancy Childbirth, 12, 1-13. http://www.biomedcentral.com/1471-2393/12/66

[9] Ministère de la santé (2000) Plan directeur de developpement sanitaire 2000-2009. Ministère de la santé, Kinshasa.

[10] Ministère de la santé (2006) Recueil des Normes de la ZS 30 août 06 lecture Adrien. Ministère de la santé, Kinshasa.

[11] Organisation Mondiale de la Santé (2000) Pour un meilleur accès à des services à des soins de qualité en matière de planification familiale: Critères de recevabilité pour l'adoption et l'utilisation continue de méthodescontraceptives. 2nd Edition, Santé et recherche génésique, Geneve, 1-142.

[12] Shireen, A., Wang, Z.J. and Mallick, L. (2015) Qualité des soins dans les services de planification familiale dans les établissement de santé au Sénégal: Études Analytiques des EDS 55.

[13] Programme national de santé de la reproduction (209) Conference National sur le repositionnement PF. Programme national de santé de la reproduction, Kinshasa.

[14] Ministère de la santé (2014) Planification familiale: Plan strétegique national à vision multisectoriel (2014-2020). Ministère de la santé, Kinshasa.

[15] Hanefeld, J., Powell-jackson, T. and Balabanova, D. (2017) Understanding and Measuring Quality of Care : Dealing with Complexity. Bulletin of the World Health Organization, 95, 368-374. https://doi.org/10.2471/BLT.16.179309

[16] CDC, U.S. Department of Health and Human Services (2014) Providing Quality Family Planning Services. Morbidity and Mortality Weekly Report, 63, 1-29.

[17] Chenge, M., Van Der Vennet, J. and Porignon, D. (2010) La carte sanitaire de la ville de Lubumbashi, République Démocratique du Congo Partie I: Problématique de la couvertues sanitaire en milieu urbain congolai. Global Health Promotion, 17, 63-74. https://doi.org/10.1177/1757975910375173

[18] Shaw, B., Dc, W., Littrell, M., Pope, J., Rahariniaina, J., Shaw, B., et al. (2107) Document de référence de l'étude FPwatch République Démocratique du Congo Enquête sur les lieux de prestation de service. Kinshasa, RD Congo.

[19] Mpunga, D., Lumbayi, J.P., Dikamba, N., Mwembo, A., Ali Mapatano, M. and Wembodinga, G. (2017) Availability and Quality of Family Planning Services in the 
Democratic Republic of the Congo: High Potential for Improvement. Global Health: Science and Practice, 5, 274-285. https://doi.org/10.9745/GHSP-D-16-00205

[20] Bertrand, J.T., Kayembe, P., Dikamba, N., Mafuta, E., Hernandez, J., Hellen, J., et al. (2014) Using Mapping of Service Delivery Sites to Increase Contraceptive Availability in Kinshasa, Democratic Republic of the Congo. International Perspectives on Sexual and Reproductive Health, 40, 95-99.

https://doi.org/10.1363/4009514

[21] Fallon, J.B. (2017) Availability of Family Planning Services and Quality of Counseling by Faith-Based Organizations: A Three Country Comparative Analysis. Reproductive Health, 14, 1-11.

[22] Ministère de la santé (2006) Stratégie de renforcement du système de santé (SRSS). Kinshasa, RD Congo.

[23] Agha, S. and Do, M.A.I. (2018) The Quality of Family Planning Services and Client Satisfaction in the Public and Private Sectors in Kenya. International Journal for Quality in Health Care, 21, 87-96.

[24] Hutchinson, P.L., Do, M. and Agha, S. (2011) Measuring Client Satisfaction and the Quality of Family Planning Services: A Comparative Analysis of Public and Private Health Facilities in Tanzania, Kenya and Ghana. BMC Health Services Research, 11, 203. http://www.biomedcentral.com/1472-6963/11/203

https://doi.org/10.1186/1472-6963-11-203 